\title{
QTL mapping for field resistance to wheat blast in the Caninde\#1/ Alondra population
}

\author{
Xinyao He ${ }^{1} \cdot$ Muhammad Rezaul Kabir ${ }^{2} \cdot K$ Kishna K. Roy ${ }^{2} \cdot$ Md. Babul Anwar ${ }^{2} \cdot K^{\prime}$ aijie Xu ${ }^{3} \cdot$ Felix Marza ${ }^{4}$. \\ Firuz Odilbekov ${ }^{5} \cdot$ Aakash Chawade $^{5}$. Etienne Duveiller ${ }^{1}$ - Eric Huttner ${ }^{6} \cdot$ Pawan K. Singh $^{1}$ (I)
}

Received: 28 February 2020 / Accepted: 23 May 2020 / Published online: 2 June 2020

(c) The Author(s) 2020

\begin{abstract}
Key message Wheat blast resistance in Caninde\#1 is controlled by a major QTL on 2NS/2AS translocation and multiple minor QTL in an additive mode.

Abstract Wheat blast (WB) is a devastating disease in South America, and it recently also emerged in Bangladesh. Host resistance to WB has relied heavily on the 2NS/2AS translocation, but the responsible QTL has not been mapped and its phenotypic effects in different environments have not been reported. In the current study, a recombinant inbred line population with 298 progenies was generated, with the female and male parents being Caninde\#1 (with 2NS) and Alondra (without 2NS), respectively. Phenotyping was carried out in two locations in Bolivia, namely Quirusillas and Okinawa, and one location in Bangladesh, Jashore, with two sowing dates in each of the two cropping seasons in each location, during the years 2017-2019. Genotyping was performed with the DArTseq ${ }^{\circledR}$ technology along with five previously reported STS markers in the 2NS region. QTL mapping identified a major and consistent QTL on 2NS/2AS region, explaining between 22.4 and $50.1 \%$ of the phenotypic variation in different environments. Additional QTL were detected on chromosomes 1AS, 2BL, $3 \mathrm{AL}, 4 \mathrm{BS}, 4 \mathrm{DL}$ and 7BS, all additive to the 2NS QTL and showing phenotypic effects less than 10\%. Two codominant STS markers, WGGB156 and WGGB159, were linked proximally to the 2NS/2AS QTL with a genetic distance of $0.9 \mathrm{cM}$, being potentially useful in marker-assisted selection.
\end{abstract}

Communicated by Lee Hickey.

Electronic supplementary material The online version of this article (https://doi.org/10.1007/s00122-020-03624-x) contains supplementary material, which is available to authorized users.

Pawan K. Singh

pk.singh@cgiar.org

1 International Maize and Wheat Improvement Center (CIMMYT), Apdo. Postal 6-641, 06600 Mexico, DF, Mexico

2 Bangladesh Wheat and Maize Research Institute (BWMRI), Nashipur, Dinajpur, Bangladesh

3 Institute of Cotton Research, Chinese Academy of Agricultural Sciences, Anyang, Henan, China

4 Instituto Nacional de Innovación Agropecuaria y Forestal (INIAF), La Paz, Bolivia

5 Department of Plant Breeding, Swedish University of Agricultural Sciences, 23053 Alnarp, Sweden

6 Australian Centre for International Agricultural Research, 38 Thynne St, Bruce, ACT 2617, Australia

\section{Introduction}

Wheat blast (WB) is an emerging and devastating disease of wheat, caused by the fungus Magnaporthe oryzae pathotype Triticum (MoT), leading to yield losses of up to $100 \%$ and grain quality deterioration, greatly threatening food security in the epidemic regions (Kohli et al. 2011; Cruz and Valent 2017). This disease first appeared in 1985 in the Paraná state of Brazil and soon spread throughout many of the important wheat-producing areas in Brazil (lgarashi et al. 1986; Goulart and Paiva 1990; Picinini and Fernandes 1990; Dos Anjos et al. 1996). Afterward, WB gradually spread to the neighboring countries of Bolivia, Paraguay and Argentina (Barea and Toledo 1996; Viedma 2005; Perelló et al. 2015) and had been confined to South America until recently. In 2016, WB was found in Bangladesh, which was its first outbreak outside South America (Malaker et al. 2016), causing yield reduction of up to 51\% in some epidemic regions (Islam et al. 2016). This confirmed the risk identified by Duveiller et al. (2011) based on the similarity of agro-climatic conditions in Bangladesh 
and parts of South America, following the severe epidemics in South America in 2009. Therefore, WB became a serious threat to the neighboring countries of Bangladesh. WB-vulnerable areas amounting to 7 million ha in India, Pakistan and Bangladesh were identified, with an estimated potential annual yield loss of about $0.89-1.77$ million tons (Mottaleb et al. 2018). With global warming, this disease might further spread to other major wheat production regions like USA, Ethiopia or Australia (Cao et al. 2011; Maciel 2011; Cruz et al. 2016a).

The pathogen has a global distribution and is regarded as the most devastating fungal pathogen worldwide (Dean et al. 2012). M. oryzae is a hemibiotrophic ascomycetous fungal species, having a series of pathotypes, among which are the widely distributed rice pathotype $\mathrm{MoO}$ and the wheat pathotype MoT (Maciel 2011; Cruz and Valent 2017). Unlike rice blast, for which research has been ongoing for many decades, WB is a relatively new disease and there are large knowledge gaps in terms of epidemiology, host-pathogen interaction, management, etc. (Duveiller et al. 2016; Cruz and Valent 2017). So far, control of WB relies essentially on fungicide applications. However, the low effectiveness of fungicide application under high disease pressure (Fernandes et al. 2017) and the high risk of development of fungal resistance to fungicides (Castroagudín et al. 2015) are two major limitations of this approach. Host resistance is another major WB management component and is more economical and environmentally friendly compared to fungicide application. Since the first WB outbreak in Brazil in the 1980s, searches for sources of resistance have been carried out, but many the resistant lines identified in the early days became susceptible, due to the fast evolution of MoT (Duveiller et al. 2016). Nevertheless, varieties showing lasting resistance or tolerance to WB in South America have been identified: BR 18 and CD 116 in Brazil, Caninde\#1 and Itapua 75 in Paraguay, and Montacu and Urubo in Bolivia (Ha et al. 2012; Buerstmayr et al. 2017). Many of those lines were derived from the CIMMYT wheat line Milan and have the 2NS/2AS translocation that is further discussed.

So far, most genetic studies for WB resistance were performed at the seedling stage, where the host-pathogen interaction appeared to follow the gene-for-gene model (Anh et al. 2015). The resistance genes identified in such experiments are $R m g 2, R m g 3, R m g 7, R m g 8, R m g T d(t)$ and RmgGR119 (Zhan et al. 2008; Cumagun et al. 2014; Tagle et al. 2015; Cruz et al. 2016b; Wang et al. 2018a) for host resistance against MoT, and Rmg1, Rmg4, Rmg5, Rmg6 (Hau et al. 2007; Nga et al. 2009; Vy et al. 2014) for resistance against non-MoT strains of M. oryzae. Of these genes, $R m g 7, R m g 8$ and RmgGR119 also conferred resistance at the adult plant stage against spike infection by MoT, but Cruz and Valent (2017) pointed out that the resistance conferred by $R m g 7$ has been overcome by recent MoT isolates, whereas $R m g 8$ and $R m g G R 119$ remain to be tested with the new MoT isolates.

Genetics for field WB resistance is much less researched compared to that for seedling resistance, but it is generally accepted that quantitative resistance predominates in this pathosystem, as a continuous variation was observed among the evaluated germplasm (Maciel et al. 2014; Cruz et al. 2016b). So far, the only known effective field WB resistance source is $2 \mathrm{NS} / 2 \mathrm{AS}$ translocation. The $2 \mathrm{NS}$ chromosomal segment was introduced from Aegilops ventricosa (Zhuk.) to replace the distal region of $2 \mathrm{AS}$ in wheat, in order to utilize the rust resistance genes $\mathrm{Lr37}$, Sr38, and $\mathrm{Yr} 17$ (Helguera et al. 2003). Later, it was found that other resistance genes, including $\mathrm{Cre} 5$ for cereal cyst nematode resistance (Jahier et al. 2001) and $R k n 3$ for root-knot nematodes resistance (Williamson et al. 2013), are present in this segment. Recently, Cruz et al. (2016b) reported the significant effects of $2 \mathrm{NS}$ in WB resistance, which conferred $64-81 \%$ reduction in head blast severity in both spring and winter wheat. Juliana et al. (2019) further demonstrated the important role of $2 \mathrm{NS}$ in conferring WB resistance in CIMMYT germplasm, along with an additional finding that the 2NS lines have a significant yield advantage.

The main objectives of the current study were to map QTL for field WB resistance in a bread wheat recombinant inbred line (RIL) population Caninde\#1/Alondra and to identify molecular markers linked to the QTL for their potential use in marker-assisted selection (MAS).

\section{Materials and methods}

\section{Plant material}

A RIL population of $298 \mathrm{~F}_{2: 7}$ progenies, derived from a cross between Caninde\#1 and Alondra, was developed by single seed descend. The female parent Caninde\#1 has a pedigree of Milan/Munia, carries the 2NS/2AS translocation and shows consistently good WB resistance (Kohli et al. 2011). The male parent Alondra has a pedigree of D-6301/ NAINARI-60//WEIQUE/RED-MACE/3/CIANO-F-67*2/ CHRIS, does not carry the 2NS/2AS translocation and is susceptible to WB.

\section{Inoculum preparation}

The protocol was modified from Cruz et al. (2016b). A fungal plug of $5 \mathrm{~mm}$ was taken from a Petri dish culturing the MoT isolate and was then transferred onto plates with oatmeal agar that was prepared following the below steps. Fifty grams of rolled oats was added into $800 \mathrm{ml}$ of distilled water, which was boiled for 5 min with a magnetic stirrer, filtered through four layers of cheesecloth and adjusted to 
$1 \mathrm{~L}$ with distilled water. Finally, $15 \mathrm{~g}$ of agar was added before autoclave. Agar plates with the MoT isolate were incubated under $18-28{ }^{\circ} \mathrm{C}$ with $12 \mathrm{~h}$ of light/dark photoperiod. Seven days later, mycelium grown on the plates was scraped off with a spatula and the plates were cultivated for three more days under continuous light to induce sporulation. Upon conidia harvest, the plates were flooded with $10 \mathrm{ml}$ of autoclaved distilled water and gently scraped with a brush. The spore suspension was collected in a test tube and was vortexed briefly to separate conidia and mycelia, and the latter was discarded via filtering through two layers of cheesecloth. The inoculum was adjusted to 80,000 conidia/ $\mathrm{ml}$ with a hemocytometer under a microscope, and then, Tween-20 was added to make a concentration of $0.02 \%$ for field application.

\section{Field experiments}

Field trials took place in three locations, i.e., Quirusillas and Okinawa in Bolivia and Jashore in Bangladesh. Quirusillas is in the high land region of the Department of Santa Cruz, Bolivia, at an altitude of $1496 \mathrm{~m}$ above sea level (masl), with a cropping cycle from December to April. Okinawa is located in the lowland region of the Department of Santa Cruz, Bolivia, at an altitude of 267 masl, where the cropping cycle is from May to August. Jashore is in the southwestern region of Bangladesh, at an altitude of 7 masl, with a cropping season from December to April. The population was evaluated in two cropping cycles in each of the three locations, i.e., the 2017-2018 and 2018-2019 cycles in Quirusillas and Jashore and the 2018 and 2019 cycles in Okinawa, with two sowing dates (10 days difference) in each cropping cycle to expose the population to different environments. The experiments were then named according to the location, cropping cycle and sowing date, where 'Quir' stands for Quirusillas, 'Jash' for Jashore and 'Oki' for Okinawa, ' 18 ' and ' 19 ' for 2017-2018 or 2018 cycle and 2018-2019 or 2019 cycle, respectively, and ' $a$ ' and 'b' for the first and second sowing, respectively. For example, the experiment 'Quir19b' represents the second sown experiment carried out in Quirusillas in the 2018-2019 cycle.

The materials were sown in 1-m double rows spaced 20 $\mathrm{cm}$ apart, and no replication was made within each sowing. In Bolivia, Urubo and Atlax were used as resistant and susceptible checks, respectively, whereas in Bangladesh, the corresponding checks were BARI Gom 33 and BARI Gom 26. A misting system was set up in the nurseries, working from 8 am to $7 \mathrm{pm}$, with $10 \mathrm{~min}$ of spraying each hour to keep a humid microenvironment that is conducive for WB infection. A mixture of locally collected MoT isolates was used for field inoculation, including OKI1503, OKI1704, QUI1505, QUI1601, QUI1612 in Bolivia and BHO17001, MEH17003, GOP17001.2, RAJ17001, CHU16001.3,
JES16001 in Bangladesh. The isolates were selected based on their capacity of high sporulation. Inoculation was targeted to the anthesis stage of each line and was repeated 2 days later, where the inoculum was applied in the evening at a concentration of 80,000 spores $/ \mathrm{mL}$, using a $\mathrm{CO}_{2}$-driven backpack sprayer. WB evaluation was performed at 14 or 21 days after the first inoculation, depending on the disease development, on 10 spikes that had been tagged at anthesis. Upon evaluation, the total and infected number of spikelets were counted for each of the 10 spikes, and then WB index was calculated with the formula WB index $=$ Incidence $\times$ Severity, where Incidence stands for the percentage of spike with WB symptom and Severity for the averaged percentage of infected spikelets. Days to heading (DH) and plant height $(\mathrm{PH})$ were scored in all the experiments.

\section{Statistical analysis}

The SAS program ver. 9.2 was used to conduct analysis of variance (ANOVA), with its PROC GLM module, whereas the calculation of Pearson's correlation coefficients was carried out using the PROC CORR function. The ANOVA results were used for calculating the heritability estimates, with the formula $H^{2}=\sigma_{\mathrm{g}}^{2} /\left(\sigma_{\mathrm{g}}^{2}+\sigma_{\mathrm{g} * y}^{2} / y+\sigma_{\mathrm{g} * s}^{2} / s+\sigma_{\mathrm{e}}^{2} / s y\right)$, where $\sigma_{\mathrm{g}}^{2}$ represents genetic variance, $\sigma_{\mathrm{g} * y}^{2}$ for genotype-by-year interaction, $\sigma_{\mathrm{g} * s}^{2}$ for genotype-by-sowing interaction, $\sigma_{\mathrm{e}}^{2}$ for error variance, $y$ for the number of years and $s$ for the number of sowing dates.

\section{Genotyping}

Genomic DNA was extracted from young leaves of 2-weekold plants with the CTAB method. RILs of the population were genotyped with the DArTseq ${ }^{\circledR}$ technology at the Genetic Analysis Service for Agriculture (SAGA) at CIMMYT, Mexico. Additionally, five STS markers in the 2NS/2AS region were used in this study, and they are Ventriup-LN2 developed by Helguera et al. (2003), WGGB156 and $W G G B 159$ by Wang et al. (2018b), IWB11136 by Xue et al. (2018) and cslVrgal3 that was derived from a follow-up study of Seah et al. (2001) (E. Lagudah, pers. comm.). Markers with more than $20 \%$ missing data points were removed from further analysis, as well as those highly distorted with a minor allele frequency less than $30 \%$. Redundant markers identified with the BIN module of the ICIMapping v. 4.1 software (www.isbreeding.net) were discarded.

\section{Linkage and QTL mapping}

Linkage groups (LG) were generated with the JoinMap v.4 software (Van Ooijen 2006), with LOD scores from 5 to 10 for grouping and the maximum likelihood algorithm 
for ordering within each LG. Chromosome anchoring of LGs was obtained via BLASTing sequences of the DArTseq markers against the Chinese Spring genome (IWGSC RefSeq v1.0). QTL analysis was conducted with MapQTL v6.0 (Van Ooijen 2009), in which interval mapping (IM) was first tried to detect potential QTL for a trait as well as the most closely linked markers to those QTL. Subsequently, multiple QTL mapping (MQM) for each QTL was carried out, using the tightly linked markers as cofactors. Significant QTL were defined in this study when they have a LOD score of $>3.0$ in at least one environment or over the threshold of 2.0 in multiple environments. The software MapChart ver. 2.3 (Voorrips 2002) was used to draw LGs and LOD curves.

\section{Results}

\section{Phenotyping}

WB index varied greatly across the 12 environments, with Quir18a being the lowest with a grand mean of WB index of $18.5 \%$ and Oki19a the highest with $56.1 \%$. The disease variation corresponded generally well with the climatic data, where warmer and higher precipitation in February (Quirusillas and Jashore) or July (Okinawa) favored WB infection (Fig. S1). The resistant parent Caninde\#1 showed consistently lower WB infection than the susceptible parent Alondra, with their respective WB index ranged from 0 to $32 \%$ and 45 to $100 \%$ across environments. Transgressive segregation was often observed, in both the resistant and susceptible directions (Fig. 1). ANOVA indicated significant effects of 'Genotype' as well as those of 'Genotype $\times$ Year' in all three locations, and moderately high heritability estimates were obtained that ranged from 0.71 for Quirusillas to 0.87 for Okinawa (Table 1). Phenotypic correlations of WB were all significant among experiments, with $r$-values ranging from 0.41 to 0.87 . In general, higher correlation coefficients were found among experiments in Bolivia, whereas lower correlation coefficients were observed among experiments in Bangladesh (Table 2).

In Okinawa, late-sown experiments exhibited consistently lower WB than the earlier-sown ones, whereas the trends were less clear in Quirusillas and Jashore (Fig. 1). Correlation of WB with $\mathrm{DH}$ and $\mathrm{PH}$ was either nonsignificant or significant at low levels (Table 3). Of the significant correlations between WB and DH, those in Jashore experiments
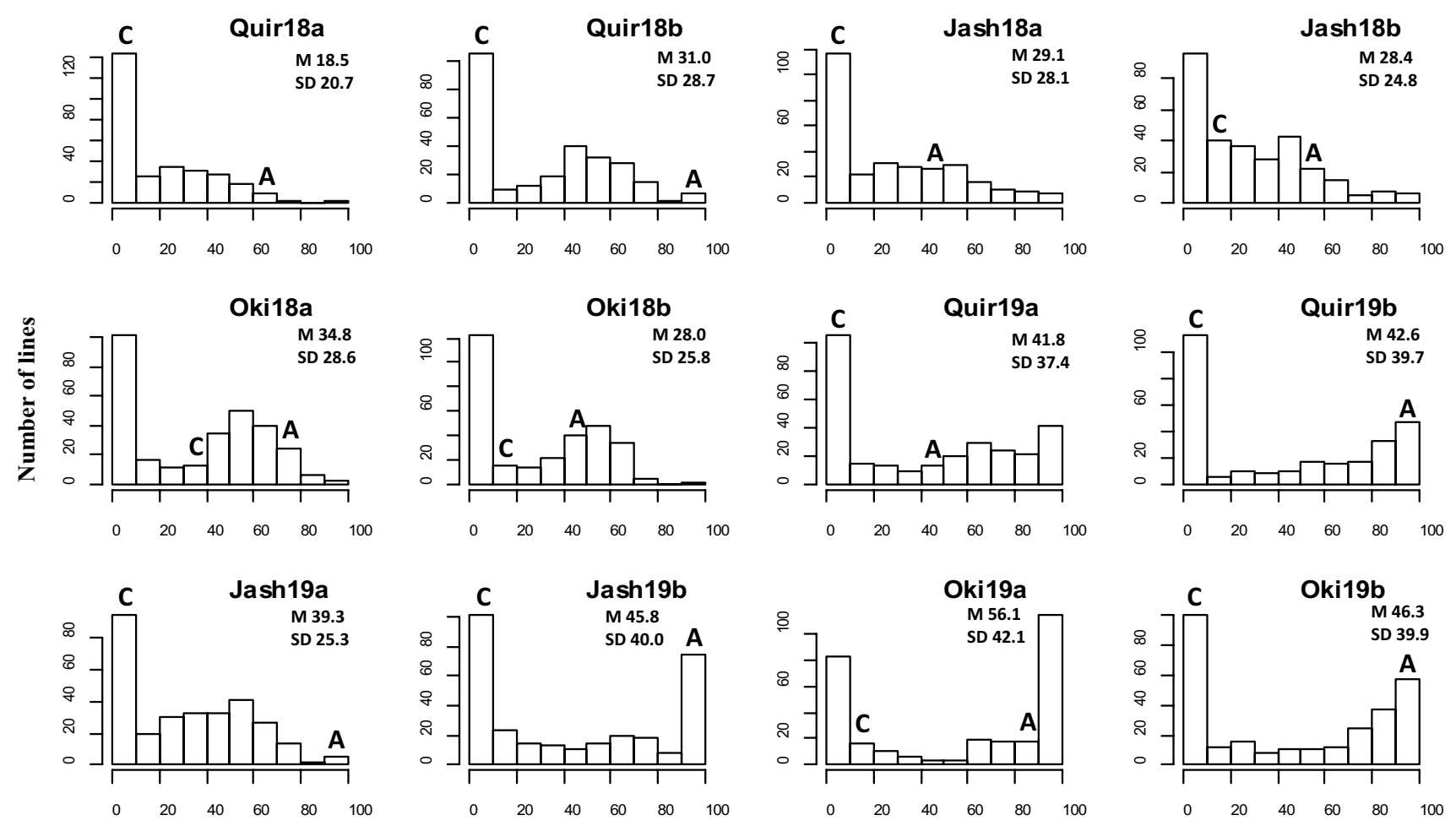

Wheat blast index (\%)

Fig. 1 Histograms of wheat blast index in the Caninde\#1/Alondra population in individual environments. Phenotypic ranges of the two parents are indicated, where $C$ stands for Caninde\#1 and $A$ for Alondra. 'Quir' stands for Quirusillas, 'Jash' for Jashore and 'Oki' for
Okinawa, '18' and ' 19 ' for the 2017-2018 or 2018 cycle and 20182019 or 2019 cycle, respectively, and ' $a$ ' and 'b' for the first and second sowing, respectively. Grand mean (M) and standard deviation (SD) values are presented for all experiments 
Table 1 Analysis of variance for wheat blast index in different locations and its heritability estimates

\begin{tabular}{llrrrrr}
\hline Location & Source & DF & Mean square & $F$ value & $P$ value & Heritability \\
\hline Quirusillas & Genotype & 297 & 2641.00 & 10.68 & $<0.0001$ & 0.71 \\
& Year & 1 & $74,437.42$ & 301.01 & $<0.0001$ & \\
& Sowing (year) & 1 & 8059.75 & 32.59 & $<0.0001$ & \\
& Genotype $\times$ year & 287 & 721.37 & 2.92 & $<0.0001$ & \\
& Genotype $\times$ sowing & 291 & 310.66 & 1.26 & 0.0336 & \\
Jashore & Error & 238 & 247.30 & & & \\
& Genotype & 297 & 2256.78 & 5.67 & $<0.0001$ & 0.74 \\
& Year & 1 & $31,555.83$ & 79.26 & $<0.0001$ & \\
& Sowing (year) & 1 & $14,699.25$ & 36.92 & $<0.0001$ & \\
& Genotype $\times$ year & 297 & 571.83 & 1.44 & 0.0009 & \\
& Genotype $\times$ sowing & 297 & 421.93 & 1.06 & 0.3086 & \\
& Error & 297 & 398.13 & & & \\
& Genotype & 297 & 3912.81 & 24.09 & $<0.0001$ & 0.87 \\
& Year & 1 & $117,455.51$ & 723.16 & $<0.0001$ & \\
& Sowing (year) & 1 & 342.04 & 2.11 & 0.1478 & \\
& Genotype $\times$ year & 294 & 440.79 & 2.71 & $<0.0001$ & \\
& Genotype $\times$ sowing & 297 & 247.29 & 1.52 & 0.0002 & \\
& Error & 282 & 162.42 & & &
\end{tabular}

Table 2 Pearson's correlation coefficients of wheat blast index among the 12 environments (color table online)

\begin{tabular}{|c|c|c|c|c|c|c|c|c|c|c|c|}
\hline & Quir18a & Quir18b & Jash 18a & Jash $18 b$ & Oki18a & Oki18b & Quir19a & Quir19b & Jash 19a & Jash 19b & Oki19a \\
\hline Quir18b & 0.69 & 1 & & & & & & & & & \\
\hline Jash 18a & 0.44 & 0.51 & 1 & & & & & & & & \\
\hline Jash $18 b$ & 0.41 & 0.51 & 0.58 & 1 & & & & & & & \\
\hline Oki18a & 0.59 & 0.62 & 0.56 & 0.58 & 1 & & & & & & \\
\hline Oki18b & 0.59 & 0.63 & 0.50 & 0.58 & 0.74 & 1 & & & & & \\
\hline Quir19a & 0.56 & 0.55 & 0.45 & 0.50 & 0.74 & 0.73 & 1 & & & & \\
\hline Quir19b & 0.55 & 0.57 & 0.47 & 0.50 & 0.74 & 0.70 & 0.77 & 1 & & & \\
\hline Jash 19a & 0.48 & 0.46 & 0.47 & 0.45 & 0.58 & 0.55 & 0.58 & 0.60 & 1 & & \\
\hline Jash 19b & 0.47 & 0.54 & 0.49 & 0.52 & 0.64 & 0.60 & 0.62 & 0.60 & 0.59 & 1 & \\
\hline Oki19a & 0.62 & 0.64 & 0.57 & 0.61 & 0.83 & 0.79 & 0.82 & 0.78 & 0.64 & 0.69 & 1 \\
\hline Oki19b & 0.57 & 0.61 & 0.50 & 0.59 & 0.77 & 0.79 & 0.80 & 0.73 & 0.63 & 0.62 & 0.87 \\
\hline
\end{tabular}

All correlations were significant at $P<0.0001$. 'Quir' stands for Quirusillas, 'Jash' for Jashore and 'Oki' for Okinawa, ' 18 ' and '19' for the 2017-2018 or 2018 cycle and 2018-2019 or 2019 cycle, respectively, and 'a' and 'b' for the first and second sowing, respectively. Cell shades change from green to red with the increase of correlation coefficients

Table 3 Phenotypic correlation of wheat blast index with days to heading $(\mathrm{DH})$ and plant height $(\mathrm{PH})$ in individual environments

\begin{tabular}{llcrccccccccc}
\hline & Quir18a & Quir18b & Jash18a & Jash18b & Oki18a & Oki18b & Quir19a & Quir19b & Jash19a & Jash19b & Oki19a & Oki19b \\
\hline DH & $0.15^{*}$ & 0.03 & $0.21^{* *}$ & 0.03 & 0.07 & -0.05 & $-0.25^{* *}$ & -0.14 & $0.2^{* *}$ & $0.17^{* *}$ & -0.06 & $-0.21^{* *}$ \\
PH & 0.04 & -0.08 & $-0.32^{* *}$ & $-0.26^{* *}$ & -0.04 & -0.07 & $-0.14^{*}$ & -0.02 & -0.08 & $-0.19^{* *}$ & $-0.26^{* *}$ & $-0.36^{* *}$ \\
\hline
\end{tabular}

'Quir' stands for Quirusillas, 'Jash' for Jashore and 'Oki' for Okinawa, '18' and '19' for the 2017-2018 or 2018 cycle and $2018-2019$ or 2019 cycle, respectively, and 'a' and 'b' for the first and second sowing, respectively

$* p<0.01 ; * * p<0.001$ 
were always positive, whereas those in Quirusillas and Okinawa experiments were all negative, except for Quir18a. In the case of $\mathrm{PH}$, however, all significant correlations were negative (Table 3 ), implying that tall plants tended to have a low level of WB.

\section{Genotyping and linkage analysis}

Initially, 78,255 SNP markers were scored for this population, and finally, 2131 non-redundant markers of high quality were used for subsequent analysis. Thirty-six LGs were generated, representing all 21 wheat chromosomes, of which 2B had the highest number of markers (301) and 4D had the lowest number of markers (16), whereas only four markers remained unlinked. These LGs covered a total genetic distance of $4851 \mathrm{cM}$, with an average distance between markers of $2.3 \mathrm{cM}$.

\section{QTL mapping}

Seven QTL have been identified on chromosomes 1AS, 2AS, 2BL, 3AL, 4BS, 4DL and 7BS, of which only the one on 2NS/2AS was consistently significant across environments, explaining phenotypic variation from 22.4 to $50.1 \%$, whereas other QTL were of minor effects and were significant in only a subset of experiments (Table 4). The QTL on 7BS was significant in nine out of 12 experiments, being the second most stable QTL and explaining phenotypic variation from 3.7 to $7.4 \%$. The remaining minor QTL were significant in two (1AS) to six (4BS) experiments. Caninde\#1 contributed resistant alleles of the QTL on 2NS/2AS, 1AS and 4DL, whereas the susceptible parent Alondra contributed those of the remaining four QTL (Table 4). It is noteworthy that the QTL on 4BS was linked to a QTL for PH in the Rht$B 1$ region (Fig. S2), whereas none of the remaining QTL showed any association with PH or DH (data not shown). Boxplot chart showing phenotypic effects of stacking different QTL exhibited clear-cut results between groups with and without 2NS, demonstrating the dominant role of 2NS in conferring WB resistance in this population (Fig. 2). Within 2NS or non-2NS group, however, minor QTL showed additive effects, i.e., the more QTL stacked, the lower the average or median WB index (Fig. 2).

\section{The 2NS QTL and its associated markers}

The 2NS/2AS translocation segment corresponds to a 16.0-cM region on the distal part of the $2 \mathrm{~A} \mathrm{LG}$, and the WB-resistant QTL was mapped between DArTseq markers 3958902 and 1209870 , corresponding to a $1.2-\mathrm{cM}$ region (Fig. 3). The five STS markers were found in the flanking regions of this QTL, with Ventriup-LN2 and cslVrgal3 in its distal region with genetic distances of 3.6 and

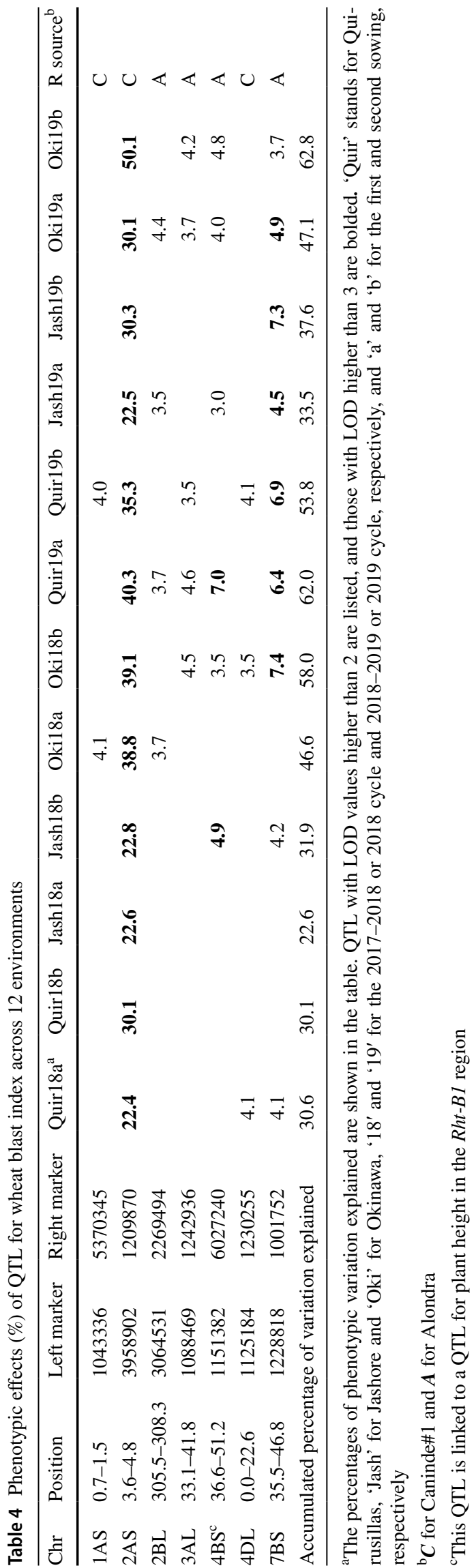




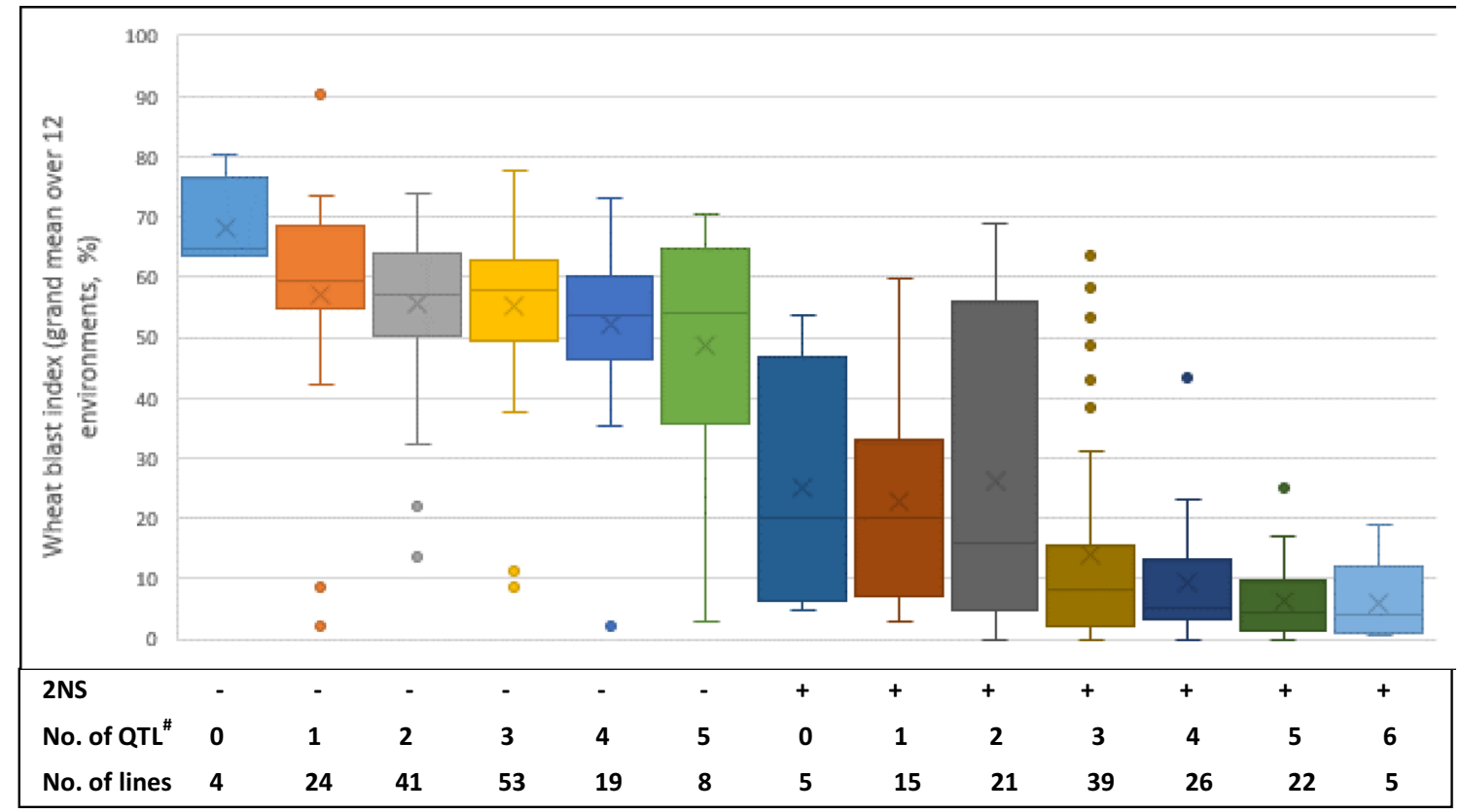

Fig. 2 Phenotypic effects of 2NS and its combinations with different numbers of minor QTL identified in this study. The allelic status of 2NS was determined by the two flanking markers 3958902 and 1209870, and other markers in the QTL region as well as phenotypic data were also considered when missing or recombination happened between the two markers. Cross and horizontal lines in each box denote the mean and median values, respectively. \# only non-2NS QTL were counted

\section{Chr2A}

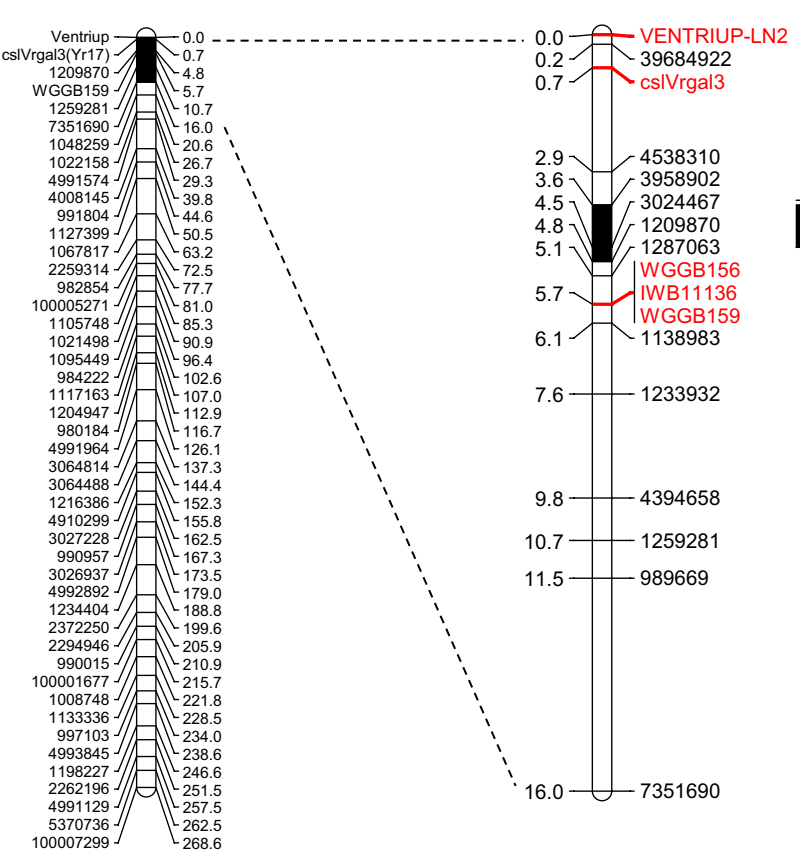

Fig. 3 QTL profile for wheat blast resistance on chromosome 2NS/2AS across environments. Genetic distances are shown in centimorgans to the inner sides of the linkage groups (LG). Only framework markers are presented on the $2 \mathrm{~A}$ LG, whereas all mapped mark- ers are shown on the 2NS/2AS LG, where non-SNP markers are highlighted in red. A threshold of 3.0 is indicated by a dashed vertical line in the LOD graph. The profiles of the remaining QTL are presented in Fig. S2 (color figure online) 
$2.9 \mathrm{cM}$, respectively, and the three co-segregating markers WGGB159, WGGB179 and IWB11136 in its proximal side with a genetic distance of $0.9 \mathrm{cM}$ (Fig. 3).

\section{Discussion}

WB resistance of a wheat line can vary greatly under different environmental conditions; thus, an appropriate disease pressure is needed to clearly differentiate the genotypes under evaluation. Mostly, WB pressure under natural infection is insufficient to correctly assess lines for their resistance levels. Early breeding work for WB resistance in South America relied mostly on natural infection, which happened sporadically across years and often unevenly in the experimental fields, enabling some genotypes to escape the infection and appear resistant or tolerant (Kohli et al. 2011; Duveiller et al. 2016). This, along with the gain of virulence of newly emerged MoT isolates, could be the most important reasons explaining that early-suggested WB resistant lines turned out to be susceptible in later evaluations. In the current study, the first field evaluation took place in the 2017 cycle in Okinawa (denoted as Oki17), under natural infection. However, the WB infection was very weak, with about half of the population showing no symptom and a grand mean of WB index of merely $1.9 \%$, and there was no significant correlation between Oki17 and those presented in Table 2. Likewise, the 2NS/2AS QTL for Oki17 was of minor effect with phenotypic effect of only $7.0 \%$ (data not shown), much smaller than from other environments. Therefore, Oki17 was not used in this study. Quirusillas is another hot spot of WB in Bolivia, where researchers and breeders have set up WB screening nurseries. Some breeding materials were sown there in the 2016-2017 cycle without artificial inoculation nor misting system, and the results turned out to be unsatisfactory (data not shown). This shows that artificial inoculation and misting are indispensable for obtaining robust phenotypic data of WB, even in hot spots like Quirusillas and Okinawa. Therefore, artificial inoculation and misting have been adopted in the two screening sites in Bolivia since 2018, as well as in Jashore, Bangladesh, upon the establishment of WB screening nursery in the 2017-2018 cropping cycle. It is noticeable that even with artificial inoculation and misting system, WB development was not very high in several environments, like Quir18a and Jash18b (Fig. 1). Considering also the significant genotypeby-environment interaction, field evaluation for WB must be performed in multiple environments (preferably in different locations across years) in order to obtain robust phenotypic results.

It is well accepted that early-sown materials usually get heavier WB infection than the late-sown ones in South America; thus, it is not suggested to plant wheat too early in order to avoid the WB infection (Goulart et al. 1990; Cruz and Valent 2017). This rule, however, was based on prevailing weather conditions, whereas in a specific cropping cycle it may not be true. For example, during the 2017-2018 cropping season in Quirusillas, a reverse trend was observed. Nevertheless, data from Okinawa agreed well with the general trend (Fig. 1). In South Asia, temperature and rainfall during the late part of the wheat season are expected to increase and become more conducive for WB; thus, latesown or late-headed lines are expected to have more severe WB infection, as shown by our results (Table 3, Fig. 1). Therefore, a recommendation to South Asian farmers in terms of WB would be to avoid planting the crop late, which agrees well with the avoidance of spot blotch and terminal heat (Joshi et al. 2007).

Plant height has shown a close association with Fusarium head blight (FHB), a major spike disease of wheat, with one of the underlying mechanisms being that spikes of tall plants are well ventilated and thus become drier and have lower FHB severity, compared to those of short plants (Yan et al. 2011). Considering the likewise requirement of WB for high humidity, a similar association between WB and $\mathrm{PH}$ is expected, which was demonstrated for the first time in the current study (Table 3). Notably, the WB QTL on 4BS partly overlapped with a PH QTL at Rht-B1 (Fig. S2), and this genetic linkage might have contributed to the phenotypic correlation. Apart from this QTL, none of the remaining QTL was associated with $\mathrm{PH}$, being markedly different from those for FHB (He et al. 2016; Xu et al. 2020). This might also imply that PH has less impact on WB than on FHB, but further study is needed to corroborate or negate it.

As expected, the 2NS/2AS translocation demonstrated consistent and large phenotypic effects on reducing WB infection, but its effects were not high enough to be regarded as a simple Mendelian factor. This implies that 2NS alone cannot provide complete protection against $\mathrm{WB}$, which is in agreement with Cruz et al. (2016b). In fact, the most susceptible 2NS carrier showed a grand mean of WB index close to $70 \%$, and many had a grand mean higher than $50 \%$ (Fig. 2), showing that 2NS-mediated resistance is highly dependent on the genetic background, where other factor(s) might be required to fulfill its function. The breakdown of 2NS resistance to WB has been reported in Paraguay (Singh et al. 2016) and Brazil (Ceresini et al. 2018). In a greenhouse experiment conducted in Bolivia, the well-known 2NS carrier Milan exhibited an average WB severity of 35\% (Marza et al. 2019). Therefore, 2NS resistance is most likely incomplete, at least under high WB pressure, and new MoT isolates appear to have higher virulence to the 2NS carriers (Cruz et al. 2016b). To achieve better and durable resistance, additional QTL are necessary. As shown in our results, the more QTL accumulated, the less WB is observed. Unfortunately, all non-2NS QTL identified in this study were of minor 
effects and would be difficult to use in a MAS strategy. It is imperative to identify novel QTL with major effects for WB resistance, so that they can be utilized in breeding to reduce the high selection pressure 2NS is exerting on the MoT population. In this regard, non-2NS genotypes identified by Cruppe et al. (2020) as resistant to WB could be analyzed in genetic studies for the discovery of new QTL. Nevertheless, without such QTL, it is still possible to obtain non-2NS lines with an acceptable level of WB resistance by stacking multiple minor QTL. Such examples can be observed from Fig. 2, where many non-2NS lines showed good WB resistance, although we should keep in mind that a few of them might be actually 2NS carriers that were mistakenly classified as non-2NS based on flanking markers, because no functional marker is currently available for this QTL. The strong phenotypic effects of multiple minor genes were well demonstrated in wheat rusts (Singh et al. 2016), but we must say that to do the same in WB is far more challenging, considering the difficulty in WB phenotyping and the small phenotypic effects of the so-far known minor QTL.

The molecular marker Ventriup-LN2 has been widely used for diagnosing the presence of the 2NS segment in hexaploid wheat with good accuracy (Helguera et al. 2003; Cruz et al. 2016b). The drawback of this marker is its dominant nature, which might lead to false-negative results when DNA quality is poor. The marker amplifies PCR product in 2NS carriers; thus, it cannot differentiate heterozygous (2NS/2AS) from homozygous (2NS/2NS) genotypes. Additionally, this marker is distal to the WB resistance QTL, with a distance of $3.6 \mathrm{cM}$ in the current mapping population, making it less diagnostic. The marker cslVrgal3 is similar to Ventriup-LN2 in all aspects. Different to these two markers, WGGB156 and WGGB159 developed by Wang et al. (2018b) are codominant, closer to the QTL, and thus could be more effective for tracking the QTL in crosses.

The WB resistance QTL from 2NS has a projected physical region of $2.3 \mathrm{Mb}$ on the $2 \mathrm{AS}$ chromosome of Chinese Spring (IWGSC RefSeq v1.0). This region harbors 79 annotated high-confidence genes, of which 14 are of NBS-LRR gene family, three are of disease resistance protein, as well as genes belong to receptor-like protein kinase, $\mathrm{ABC}$ transporter $\mathrm{G}$ family member, dirigent protein, F-box domain protein and defensin that have been associated with disease resistance in wheat. Nevertheless, the underlying gene for this QTL might not be one of them, since Chinese Spring is a $2 \mathrm{AS}$ carrier, whereas the resistance allele of this QTL comes from 2NS. However, the clusters of resistance genes in the reference genome may indicate that $2 \mathrm{NS} / 2 \mathrm{AS} \mathrm{QTL}$ region is enriched for resistance-encoding genes, which could be a hint for future investigation of the locus.

Acknowledgements Financial supports from the CGIAR Research Program on WHEAT, Indian Council of Agricultural Research, India,
Vetenskapsrådet (the Swedish Research Council), Sweden, and Australian Centre for International Agricultural Research, Australia, are gratefully acknowledged. Technical support from Jose Asister, Jhonny Villagomez, Roberto Butron and Francisco Lopez in field trials in Bolivia, Tanusree Roy and Rokshana Begum in field trials in Bangladesh, Mayela Flores in genotyping work (STS markers) at CIMMYTMexico is highly acknowledged.

Author contribution statement PS conceived and designed the experiments; MK, KR, MA, FM, XH, KX and PS performed field trials; $\mathrm{XH}, \mathrm{KX}, \mathrm{FO}$ and AC contributed to genotyping activities; EH contributed to the design and development of the phenotyping platforms and the experimental strategy; ED and PS developed plant materials; $\mathrm{XH}$ analyzed the data; $\mathrm{XH}$ and $\mathrm{KX}$ wrote the first draft of the manuscript, and all co-authors contributed and approved the final draft of the manuscript.

\section{Compliance with ethical standards}

Conflict of interest The authors declare that they have no conflict of interest.

Open Access This article is licensed under a Creative Commons Attribution 4.0 International License, which permits use, sharing, adaptation, distribution and reproduction in any medium or format, as long as you give appropriate credit to the original author(s) and the source, provide a link to the Creative Commons licence, and indicate if changes were made. The images or other third party material in this article are included in the article's Creative Commons licence, unless indicated otherwise in a credit line to the material. If material is not included in the article's Creative Commons licence and your intended use is not permitted by statutory regulation or exceeds the permitted use, you will need to obtain permission directly from the copyright holder. To view a copy of this licence, visit http://creativecommons.org/licenses/by/4.0/.

\section{References}

Anh VL, Anh NT, Tagle AG, Vy TTP, Inoue Y, Takumi S, Chuma I, Tosa Y (2015) Rmg8, a new gene for resistance to Triticum isolates of Pyricularia oryzae in hexaploid wheat. Phytopathology 105:1568-1572

Barea G, Toledo J (1996) Identificación y zonificación de Pyricularia o brusone (Pyricularia oryzae) en el cutivo de trigo en el departamento de Santa Cruz. Centro de Investigación Agrícola Tropical Informe Tecnico Proyecto de Investigacion Trigo, Santa Cruz de la Sierra, Bolivia, pp 76-86

Buerstmayr H, Mohler V, Kohli M (2017) Advances in control of wheat diseases: Fusarium head blight, wheat blast and powdery mildew. In: Langridge P (ed) Achieving sustainable cultivation of wheat volume 1: breeding, quality traits, pests and diseases pp 345-370

Cao X, Chen L, Zhou Y, Duan X (2011) Potential distribution of Magnaporthe grisea in China and the world, predicted by MaxEnt. Plant Prot (Beijing) 37:80-83

Castroagudín VL, Ceresini PC, De Oliveira SC, Reges JTA, Maciel JLN, Bonato ALV, Dorigan AF, McDonald BA (2015) Resistance to QoI fungicides is widespread in Brazilian populations of the wheat blast pathogen Magnaporthe oryzae. Phytopathology 105:284-294

Ceresini PC, Castroagudín VL, Rodrigues FÁ, Rios JA, Aucique-Pérez CE, Moreira SI, Alves E, Croll D, Maciel JLN (2018) Wheat blast: past, present, and future. Annu Rev Phytopathol 56:427-456 
Cruppe G, Cruz CD, Peterson G, Pedley K, Asif M, Fritz A, Calderon L, Lemes da Silva C, Todd T, Kuhnem P, Singh PK, Singh RP, Braun HJ, Barma NCD, Valent B (2020) Novel sources of wheat head blast resistance in modern breeding lines and wheat wild relatives. Plant Dis 104:35-43

Cruz CD, Magarey RD, Christie DN, Fowler GA, Fernandes JM, Bockus WW, Valent B, Stack JP (2016a) Climate suitability for Magnaporthe oryzae Triticum pathotype in the United States. Plant Dis 100:1979-1987

Cruz CD, Peterson GL, Bockus WW, Kankanala P, Dubcovsky J, Jordan KW, Akhunov E, Chumley F, Baldelomar FD, Valent B (2016b) The 2NS translocation from Aegilops ventricosa confers resistance to the Triticum pathotype of Magnaporthe oryzae. Crop Sci 56:990-1000

Cruz CD, Valent B (2017) Wheat blast disease: danger on the move. Trop Plant Pathol 42:210-222

Cumagun CJR, Anh VL, Vy TTP, Inoue Y, Asano H, Hyon GS, Chuma I, Tosa Y (2014) Identification of a hidden resistance gene in tetraploid wheat using laboratory strains of Pyricularia oryzae produced by backcrossing. Phytopathology 104:634-640

Dean R, Van Kan JA, Pretorius ZA, Hammond-Kosack KE, Di Pietro A, Spanu PD, Rudd JJ, Dickman M, Kahmann R, Ellis J, Foster GD (2012) The top 10 fungal pathogens in molecular plant pathology. Mol Plant Pathol 13:414-430

Dos Anjos JRN, Da Silva DB, Da Charchar MJ, Rodrigues GC, (1996) Occurrence of blast fungus (Pyricularia Grisea) on wheat and rye in the savanna region of central Brazil. Pesqu Agropecu Bras 3:79-82

Duveiller E, He X, Singh PK (2016) Wheat blast: an emerging disease in South America potentially threatening wheat production. In: Bonjean A, van Ginkel M (eds) The world wheat book, vol 3. Lavoisier, Paris, pp 1107-1122

Duveiller E, Hodson D, Sonder K, Av T (2011) An international perspective on wheat blast. Phytopathology 101:S220

Fernandes JMC, Nicolau M, Pavan W, Holbig CA, Karrei M, de Vargas F, Bavaresco JLB, Lazzaretti AT, Tsukahara RY (2017) A weather-based model for predicting early season inoculum buildup and spike infection by the wheat blast pathogen. Trop Plant Pathol 42:230-237

Goulart A, Paiva FdA (1990) Transmission of Pyricularia oryzae by wheat (Triticum aestivum) seeds. Fitopatol Bras 15:359-362

Goulart ACP, Paiva FD, Mesquita AND (1990) Occurrence of wheat blast (Pyricularia oryzae) in the state of Mato Grosso do Sul. Fitopatol Bras 15:112-114

Ha X, Wei T, Koopmann B, von Tiedemann A (2012) Microclimatic requirements for wheat blast (Magnaporthe grisea) and characterisation of resistance in wheat. In: Tielkes E (ed) Resilience of agricultural systems against crises. Cuvillier Verlag, Göttingen, p 155

Hau VTB, Hirata K, Murakami J, Nakayashiki H, Mayama S, Tosa Y (2007) Rwt4, a wheat gene for resistance to Avena isolates of Magnaporthe oryzae, functions as a gene for resistance to Panicum isolates in Japan. J Gen Plant Pathol 73:22-28

He X, Singh PK, Dreisigacker S, Singh S, Lillemo M, Duveiller E (2016) Dwarfing genes $R h t-B 1 b$ and $R h t-D l b$ are associated with both type I FHB susceptibility and low anther extrusion in two bread wheat populations. PLoS ONE 11:e0162499

Helguera M, Khan IA, Kolmer J, Lijavetzky D, Zhong-qi L, Dubcovsky J (2003) PCR assays for the Lr37-Yr17-Sr38 cluster of rust resistance genes and their use to develop isogenic hard red spring wheat lines. Crop Sci 43:1839-1847

lgarashi S, Utiamada CM, lgarashí L, Kazuma AH, Lopes R (1986) Pyricularia em trigo. 1. Ocorrencia de Pyricularla sp. no estado do Parana. Fitopatol Bras 11:351-352

Islam T, Croll D, Gladieux P, Soanes D, Persoons A, Bhattacharjee P, Hossain S, Gupta D, Rahman MM, Mahboob MG, Cook N, Salam M, Bueno Sancho V, Nunes Maciel J, Nani A, Castroagudin V, de
Assis Teodora, Reges J, Ceresini P, Ravel S, Kellner R, Fournier E, Tharreau D, Lebrun M-H, McDonald B, Stitt T, Swan D, Talbot N, Saunders D, Win J, Kamoun S, (2016) Emergence of wheat blast in Bangladesh was caused by a South American lineage of Magnaporthe oryzae. BMC Biol 14:84

Jahier A, Tanguy D, Rivoal K, Bariana HS (2001) The Aegilops ventricosa segment on chromosome 2AS of the wheat cultivar 'VPM1' carries the cereal cyst nematode resistance gene Cre5. Plant Breed 120:125-128

Joshi AK, Ortiz-Ferrara G, Crossa J, Singh G, Sharma RC, Chand R, Parsad R (2007) Combining superior agronomic performance and terminal heat tolerance with resistance to spot blotch (Bipolaris sorokiniana) of wheat in the warm humid Gangetic Plains of South Asia. Field Crops Res 103:53-61

Juliana P, Poland J, Huerta-Espino J, Shrestha S, Crossa J, Crespo-Herrera L, Toledo FH, Govindan V, Mondal S, Kumar U, Bhavani S, Singh PK, Randhawa MS, He X, Guzman C, Dreisigacker S, Rouse MN, Jin Y, Perez-Rodriguez P, Montesinos-Lopez OA, Singh D, Mokhlesur Rahman M, Marza F, Singh RP (2019) Improving grain yield, stress resilience and quality of bread wheat using large-scale genomics. Nat Genet 51:1530-1539

Kohli MM, Mehta YR, Guzman E, De Viedma L, Cubilla LE (2011) Pyricularia blast - a threat to wheat cultivation. Czech J Genet Plant 47:S130-S134

Maciel JLN (2011) Magnaporthe oryzae, the blast pathogen: current status and options for its control. In: Hemming D (ed) Plant sciences reviews. CABI, UK, pp 233-240

Maciel JLN, Ceresini PC, Castroagudin VL, Zala M, Kema GHJ, McDonald BA (2014) Population structure and pathotype diversity of the wheat blast pathogen Magnaporthe oryzae 25 years after its emergence in Brazil. Phytopathology 104:95-107

Malaker PK, Barma NC, Tewari TP, Collis WJ, Duveiller E, Singh PK, Joshi AK, Singh RP, Braun H-J, Peterson GL (2016) First report of wheat blast caused by Magnaporthe oryzae pathotype Triticum in Bangladesh. Plant Dis 100:2330

Marza F, Butrón R, Maydana A, Singh P, He X (2019) Resistance to wheat blast among cultivars under greenhouse conditions. In: Proceedings of the 1st International Wheat Congress, Saskatoon, Canada, p 106

Mottaleb KA, Singh PK, Sonder K, Kruseman G, Tiwari TP, Barma NCD, Malaker PK, Braun H-J, Erenstein O (2018) Threat of wheat blast to South Asia's food security: an ex-ante analysis. Plos One 13:e0197555

Nga NTT, Hau VTB, Tosa Y (2009) Identification of genes for resistance to a Digitaria isolate of Magnaporthe grisea in common wheat cultivars. Genome 52:801-809

Perelló A, Martinez I, Molina M (2015) First report of virulence and effects of Magnaporthe oryzae isolates causing wheat blast in Argentina. Plant Dis 99:1177

Picinini EC, Fernandes JMC (1990) Occurrence of wheat blast Pyricularía oryzae in commercial fields in the State of Rio Grande do Sul Brazil. Fitopatol Bras 15:83-84

Seah S, Bariana H, Jahier J, Sivasithamparam K, Lagudah ES (2001) The introgressed segment carrying rust resistance genes $\mathrm{Yr} 17$, Lr37 and $S r 38$ in wheat can be assayed by a cloned disease resistance gene-like sequence. Theor Appl Genet 102:600-605

Singh RP, Singh PK, Rutkoski J, Hodson DP, He X, Jørgensen LN, Hovmøller MS, Huerta-Espino J (2016) Disease impact on wheat yield potential and prospects of genetic control. Annu Rev Phytopathol 54:303-322

Tagle AG, Chuma I, Tosa Y (2015) Rmg7, a new gene for resistance to Triticum isolates of Pyricularia oryzae identified in tetraploid wheat. Phytopathology 105:495-499 
Van Ooijen J (2006) JoinMap® 4, software for the calculation of genetic linkage maps in experimental populations. Kyazma BV, Wageningen, Netherlands

Van Ooijen J (2009) MapQTL® 6, software for the mapping of quantitative trait loci in experimental populations of diploid species. Kyazma BV, Wageningen, Netherlands

Viedma L (2005) Wheat blast occurrence in Paraguay. Phytopathology $95: 152$

Voorrips RE (2002) MapChart: software for the graphical presentation of linkage maps and QTLs. J Hered 93:77-78

Vy TTP, Hyon GS, Nga NTT, Inoue Y, Chuma I, Tosa Y (2014) Genetic analysis of host-pathogen incompatibility between Lolium isolates of Pyricularia oryzae and wheat. J Gen Plant Pathol 80:59-65

Wang S, Asuke S, Vy TTP, Inoue Y, Chuma I, Win J, Kato K, Tosa Y (2018a) A new resistance gene in combination with $R m g 8$ confers strong resistance against Triticum isolates of Pyricularia oryzae in a common wheat landrace. Phytopathology 108:1299-1306

Wang Y, Zhang H, Xie J, Guo B, Chen Y, Zhang H, Lu P, Wu Q, Li M, Zhang D, Guo G, Yang J, Zhang P, Zhang Y, Wang X, Zhao H, Cao T, Liu Z (2018b) Mapping stripe rust resistance genes by BSR-Seq: $Y r M M 58$ and $Y r H Y 1$ on chromosome 2AS in Chinese wheat lines Mengmai 58 and Huaiyang 1 are $Y r 17$. Crop Journal 6:91-98
Williamson VM, Thomas V, Ferris H, Dubcovsky J (2013) An Aegilops ventricosa translocation confers resistance against root-knot nematodes to common wheat. Crop Sci 53:1412-1418

Xu K, He X, Dreisigacker S, He Z, Singh PK (2020) Anther extrusion and its association with Fusarium head blight in CIMMYT wheat germplasm. Agronomy 10:47

Xue S, Kolmer JA, Wang S, Yan L (2018) Mapping of leaf rust resistance genes and molecular characterization of the 2NS/2AS translocation in the wheat cultivar Jagger. G3: Genes Genomes Genet 8:2059-2065

Yan W, Li HB, Cai SB, Ma HX, Rebetzke GJ, Liu CJ (2011) Effects of plant height on type I and type II resistance to Fusarium head blight in wheat. Plant Pathol 60:506-512

Zhan SW, Mayama S, Tosa Y (2008) Identification of two genes for resistance to Triticum isolates of Magnaporthe oryzae in wheat. Genome 51:216-221

Publisher's Note Springer Nature remains neutral with regard to jurisdictional claims in published maps and institutional affiliations. 